\title{
Clotilde Bertoni, Scrittori giornalisti, giornalisti scrittori
}

\section{Marco Stupazzoni}

\section{Q OpenEdition}

1 Journals

\section{Edizione digitale}

URL: http://journals.openedition.org/studifrancesi/6342

DOI: 10.4000/studifrancesi.6342

ISSN: 2421-5856

\section{Editore}

Rosenberg \& Sellier

\section{Edizione cartacea}

Data di pubblicazione: 1 novembre 2010

Paginazione: 565-566

ISSN: 0039-2944

\section{Notizia bibliografica digitale}

Marco Stupazzoni, «Clotilde Bertoni, Scrittori giornalisti, giornalisti scrittori», Studi Francesi [Online], 162 (LIV | III) | 2010, online dal 30 novembre 2015, consultato il 08 janvier 2021. URL: http:// journals.openedition.org/studifrancesi/6342 ; DOI: https://doi.org/10.4000/studifrancesi.6342

Questo documento è stato generato automaticamente il 8 janvier 2021.

\section{(c) (i) $\odot$}

Studi Francesi è distribuita con Licenza Creative Commons Attribuzione - Non commerciale - Non opere derivate 4.0 Internazionale. 


\title{
Clotilde Bertoni, Scrittori giornalisti, giornalisti scrittori
}

\author{
Marco Stupazzoni
}

\section{NOTIZIA}

CLOTILDE BERTONI, Scrittori giornalisti, giornalisti scrittori, in Letteratura e giornalismo, Roma, Carocci, 2009 («Le bussole» 365. Studi linguistico-letterari), pp. 9-27; Il giornalismo tema letterario, ibid., pp. 87-130.

1 Soprattutto in questi due capitoli dell'interessante monografia che Clotilde Bertoni dedica allo studio dei rapporti tra giornalismo e letteratura si ritrova un numero significativamente ampio e articolato di riferimenti a Balzac ed alla sua attività giornalistica strettamente collegata e complementare a quella di romanziere. È, infatti, attraverso il giornalismo che il futuro autore della Comédie humaine focalizza la sua attenzione sulla contemporaneità contribuendo a distoglierlo dagli schemi e dai motivi proprî del romanzo storico: da questo punto di vista, la stampa periodica segue su più piani l'impianto della Comédie. Sviluppatasi dal giornalismo, osserva l'A., l'opera balzachiana «non rinunzia del tutto alla libertà e alla prensilità al giornalismo intrinseche; il che contribuisce a differenziarla dai mondi di invenzione autosufficienti, dotati di un fascino liscio e uniforme, e a renderla mondo narrativo aperto, in contatto e discussione costante con il proprio tempo» (p. 13).

2 Il romanzo della Comédie humaine che più d'ogni altro stabilisce un legame stretto, struggente e denso di significati con l'universo della stampa periodica è senza dubbio Illusions perdues, in cui l'asprezza dello scrittore nei confronti del giornalismo, delle sue regole, dei suoi oscuri meccanismi, dei suoi ricatti risulta inequivocabilmente documentata e riccamente argomentata. Tuttavia, precisa l'A., «l'affresco delle Illusioni è più composito di quanto trapeli dai messaggi palesi; la coscienza del potere del giornalismo oltrepassa il secco verdetto negativo per inoltrarsi nella complessità delle sue logiche» (p. 90). Se il giornalismo si configura come uno spazio minaccioso e 
corrotto, in grado di stravolgere i destini individuali, esso risulta «straordinariamente congeniale all'affrancamento da vecchi parametri di giudizio e all'incentivazione di altri tagli di scrittura» (p. 91). In tal senso, il giornalismo introduce nel romanzo una pluralità di codici e di voci che contribuiscono a far evolvere la sperimentazione giornalistica in sperimentazione letteraria. 